\title{
Validation of Refractivity Profiles Retrieved from FORMOSAT-3/COSMIC Radio Occultation Soundings: Preliminary Results of Statistical Comparisons Utilizing Balloon-Borne Observations
}

\author{
Hiroo Hayashi ${ }^{1,}$, Jun-Ichi Furumoto ${ }^{1}$, Xinan Lin $^{1}$, Toshitaka Tsuda ${ }^{1}$, Yoshinori Shoji ${ }^{2}$, \\ Yuichi Aoyama $^{3}$, and Yasuhiro Murayama ${ }^{4}$ \\ ${ }^{1}$ Research Institute for Sustainable Humanosphere, Kyoto University, Gokasho, Uji, Kyoto 611-0011, Japan \\ ${ }^{2}$ Meteorological Research Institute, Japan Meteorological Agency, 1-1 Nagamine, Tukuba, Ibaraki 305-0052, Japan \\ ${ }^{3}$ National Institute of Polar Research, 1-9-10 Kaga, Itabashi-ku, Tokyo 173-8515, Japan \\ ${ }^{4}$ National Institute of Information and Communications Technology, 4-2-1 Nukui-Kitamachi, Koganei, Tokyo 184-8759, Japan
}

Received 12 September 2007, accepted 21 January 2008

\begin{abstract}
The GPS radio occultation (RO) soundings by the FORMOSAT-3/COSMIC (Taiwan's Formosa Satellite Misssion \#3/Constellation Observing System for Meteorology, Ionosphere and Climate) satellites launched in mid-April 2006 are compared with high-resolution balloon-borne (radiosonde and ozonesonde) observations. This paper presents preliminary results of validation of the COSMIC RO measurements in terms of refractivity through the troposphere and lower stratosphere. With the use of COSMIC RO soundings within 2 hours and $300 \mathrm{~km}$ of sonde profiles, statistical comparisons between the collocated refractivity profiles are performed for some tropical regions (Malaysia and Western Pacific islands) where moisture-rich air is expected in the lower troposphere and for both northern and southern polar areas with a very dry troposphere. The results of the comparisons show good agreement between COSMIC RO and sonde refractivity profiles throughout the troposphere ( $1-1.5 \%$ difference at most) with a positive bias generally becoming larger at progressively higher altitudes in the lower stratosphere ( $1-2 \%$ difference around $25 \mathrm{~km}$ ), and a very small standard deviation (about $0.5 \%$ or less) for a few kilometers below the tropopause level. A large standard deviation of fractional differences in the lowermost troposphere, which reaches up to as much as $3.5-5 \%$ at $3 \mathrm{~km}$, is seen in the tropics while a much smaller standard deviation (1$2 \%$ at most) is evident throughout the polar troposphere.
\end{abstract}

Key words: GPS radio occultation, FORMOSAT-3/COSMIC, Refractivity, Validation

Citation: Hayashi, H., J. I. Furumoto, X. Lin, T. Tsuda, Y. Shoji, Y. Aoyama, and Y. Murayama, 2009: Validation of refractivity profiles retrieved from FORMOSAT-3/COSMIC radio occultation soundings: Preliminary results of statistical comparisons utilizing balloon-borne observations. Terr. Atmos. Ocean. Sci., 20, 51-58, doi: 10.3319/TAO.2008.01.21.01(F3C)

\section{INTRODUCTION}

Since the 1960s the radio occultation (RO) method has been used for the study of planetary atmospheres (e.g., Fjeldbo et al. 1971). In 1995 the GPS/MET (Global Positioning System/Meteorology) experiment employed the RO technique utilizing radio signals emitted by GPS satellites to investigate the earth's atmospheric characteristics such as refractivity, pressure, density, temperature, and humidity (Ware et al. 1996). The GPS RO measurement was followed by the German CHAMP (Challenging Minisatellite Payload

\footnotetext{
* Corresponding author

E-mail: hayashi.hiroo@jaxa.jp
}

and the Argentinean SAC-C (Satellite de Aplicaciones Cientificas-C) missions launched in 2000. About 350 - 400 RO sounding profiles per day were obtained from the two satellites (Hajj et al. 2004). The FORMOSAT-3/COSMIC (Taiwan's Formosa Satellite Mission \#3/Constellation Observing System for Meteorology, Ionosphere and Climate; hereafter COSMIC), a joint US-Taiwan project, was launched on 14 April 2006 (Rocken et al. 2000). The mission consists of six Low Earth Orbit (LEO) satellites to receive GPS radio signals in both rising and setting occultations and is expected to produce approximately $2500 \mathrm{RO}$ soundings per day. In addition, by employing the open loop 
technique for tracking GPS RO signals on the receivers, the COSMIC mission is capable of providing more data in the lowermost troposphere where the phase locked loop often fails in tracking the rapid fluctuation of RO signals (Rocken et al. 2000; Sokolovskiy 2001b; Sokolovskiy et al. 2006). Such a large influx of constantly assimilated data, distributed globally and not only over a single continent but also over the world's oceans, will improve numerical weather prediction and lead to new climate studies in areas where operational observations have not been available so far, e.g., in the troposphere over the open ocean.

It is important to examine the quality of RO soundings by comparing independent measurements. Radiosonde observations have been providing us information of atmospheric parameters such as temperature, humidity, pressure, and winds from the surface up to $20-30 \mathrm{~km}$ for over 50 years. The radiosonde network has near-global coverage and operates by taking daily or twice-daily measurements to produce profiles of atmospheric parameters with high vertical resolution (a few tens of meters). Although some errors in temperature and humidity measurements by radiosondes have been reported (e.g., Luers and Eskridge 1998; Fujiwara et al. 2003; Wang et al. 2003), they are generally considered to be the most accurate and often are used for validation of data from different sounding techniques, such as satellite-borne observations. The GPS RO soundings also have been compared against radiosonde data. Ware et al. (1996) compared, for example, 11 representative temperature profiles derived from GPS/MET (assuming a dry atmosphere) with collocated radiosonde observations (and global analyses) and found that they agree within $2 \mathrm{~K}$ from about 5 7 to $40 \mathrm{~km}$. Less than $1 \%$ mean errors with $1-2 \%$ standard deviations in refractivity differences between GPS/ MET and radiosonde in 2 to $25 \mathrm{~km}$ altitude range were reported by Rocken et al. (1997). Kuo et al. (2005) showed an interesting result of comparisons in refractivity between CHAMP $\mathrm{RO}$ and radiosonde soundings over five geographical areas, each of which uses a different type of radiosonde, and concluded that high accuracy of RO soundings could differentiate between the performance of various types of radiosonde applications.

The purpose of this paper is to present early results of the validation of COSMIC RO soundings in the troposphere and lower stratosphere. Now, although the number of sonde observations available for this study was not voluminous, we did collect high-resolution balloon-borne (radiosonde and ozonesonde) measurements to compare with the COSMIC data. The vertical profiles of refractivity were used for comparison since it is the most fundamental atmospheric property retrieved from the GPS RO signal (Kuo et al. 2005). The data used here are briefly described in section 2 along with an explanation of the comparison method. The results of statistical comparisons will be discussed in section 3 , and followed by a summary of this study in section 4 .

\section{DATA AND METHOD OF COMPARISONS}

The real-time products of the COSMIC mission are available from the COSMIC Data Analysis and Archival Center (CDAAC). Refractivity profiles are retrieved from GPS RO signals received by the COSMIC satellites using the processing procedures explained in detail by Kuo et al. (2004). The CDAAC data processing software includes four radioholographic algorithms, that is, back propagation method (Gorbunov et al. 2000), sliding spectral method (Sokolovskiy 2001a), canonical transform method (Gorbunov 2002), and full spectrum inversion (FSI) method (Jensen et al. 2003) in order to invert RO signals which passed through the moist troposphere where the multipath propagation is common and the conventional (geometric optics) method does not work. The COSMIC refractivity profiles in the lower troposphere are derived by the FSI method since it is optimal as to accuracy and computational cost. Although the COSMIC data since 21 April 2006 (a week after the launch) are available from the CDAAC, we used data after the receiver firmware update on 13 July 2006 for this validation study because of many different issues with earlier data before the day (reported in the project website, http://www .cosmic.ucar.edu/launch/status.html).

We first chose high-resolution radiosonde measurements over Malaysia for validation of the COSMIC RO soundings. The regular observations at 0000 and 1200 UTC over the six sonde sites (see Table 1) operated by Malaysian Meteorological Department were collected. The sounding data were available at every four seconds, that is, at a few tens of meters intervals in altitude. Malaysia is an equatorial country and has a tropical, humid climate characterized by the effect of two monsoon regimes, that is, the southwest monsoon from May to September and the northeast monsoon from November to March. Thus, the COSMIC RO soundings near the Malaysian sites should be influenced by a dense humidity with seasonal variations in the lower troposphere. Validation experiments in such an area are desirable to see how well refractivity profiles can be retrieved from the COSMIC RO signals propagated through the moist tro-

Table 1. List of Radiosonde Stations in Malaysia.

\begin{tabular}{lccc}
\hline \multicolumn{1}{c}{ Station } & Latitude & Longitude & Elevation $[\mathrm{m}]$ \\
\hline Kuala Lumpur & $2.73^{\circ} \mathrm{N}$ & $101.70^{\circ} \mathrm{E}$ & 17 \\
Bayan Lepas & $5.30^{\circ} \mathrm{N}$ & $100.27^{\circ} \mathrm{E}$ & 4 \\
Kota Baharu & $6.17^{\circ} \mathrm{N}$ & $102.30^{\circ} \mathrm{E}$ & 5 \\
Kuching & $1.49^{\circ} \mathrm{N}$ & $110.35^{\circ} \mathrm{E}$ & 20 \\
Bintulu & $3.12^{\circ} \mathrm{N}$ & $113.02^{\circ} \mathrm{E}$ & 23 \\
Kota Kinabalu & $5.93^{\circ} \mathrm{N}$ & $116.05^{\circ} \mathrm{E}$ & 2 \\
\hline
\end{tabular}


posphere since inhomogeneous distribution of variable humidity is expected to introduce retrieval errors (Kursinski et al. 1997; Rocken et al. 2000).

Another set of high-resolution radiosonde data came from small islands in the tropical Western Pacific (see Table 2). This area is characterized by high sea surface temperature (a.k.a. warm pool) and therefore high convective activity throughout the year with less seasonality is expected unlike the Malaysian region. The small islands are surrounded by the open ocean while the Malaysian sites are located within the Maritime Continent. Such differences in weather conditions would introduce somewhat different validations, particularly in the lower troposphere, between the two tropical areas. Operational observations (generally twice daily at 0000 and 1200UTC) at those islands, as well as other U.S.-operated stations, are processed and archived by National Oceanic and Atmospheric Administration (NOAA) National Climatic Data Center (NCDC). The data are freely available from the SPARC data center (http:// www.sparc.sunysb.edu). The measurements of atmospheric parameters are recorded every 6 seconds, which corresponds to about a 30-meter altitude resolution. For further descriptions of data refer to NCDC (1998) and Wang et al. (2005).

In addition, ozonesonde data were obtained from the World Ozone and Ultraviolet Radiation Data Center (WOUDC) for a couple of stations in the northern and southern polar areas (see Table 3). The ozonesonde observation usually includes sounding of atmospheric parameters such as temperature and humidity as well, though the launch of ozonesonde is not very frequent (usually once per week at most). Vertically high resolved profiles, with data at every few tens of meters, were available for the polar stations. One may expect better agreement between the COSMIC RO and sonde refractivities compared to the equatorial regions because the polar area is generally less humid even in the lowermost troposphere.

For validation purposes, the COSMIC RO soundings located within $300 \mathrm{~km}$ and 2 hours of balloon launches at the radiosonde and ozonesonde sites were used for the comparisons. The criterion to find collocated COSMIC soundings was defined arbitrarily and is similar to that used in previous studies (e.g., Kuo et al. 2005). A total of 47 matches were found for the Malaysian stations by the end of 2006 along with 107 matches for the Western Pacific islands. For the Antarctic stations, the ozonesonde observations until September 2007 were available and we found 19 collocated profiles at Neumayer and 15 at Syowa, respectively. Fewer ozonesonde soundings were available in the northern polar area and only a total of 11 matches were obtained from the three Arctic stations until the end of 2006.

For the sonde measurements, refractivity was estimated from temperature, pressure, and water vapor by the equation as follow:

$N=77.6 \times \frac{P}{T}+3.73 \times 10^{5} \times \frac{e}{T^{2}}$

where $N$ is refractivity in $\mathrm{N}$-unit, $T$ is temperature in Kelvin, $P$ is total air pressure in $\mathrm{hPa}$, and $e$ is partial pressure of water vapor in $\mathrm{hPa}$, respectively. Since we used the COSMIC refractivity data at a $100-\mathrm{m}$ vertical grid space, the sonde soundings were averaged in a 100-m grid box.

Fractional refractivity differences are calculated for the comparison of COSMIC RO profile with collocated sonde:

$\Delta N=\frac{N_{\text {COSMIC }}-N_{\text {Sonde }}}{N_{\text {COSMIC }}}$

where $N_{\text {COSMIC }}$ and $N_{\text {Sonde }}$ are COSMIC-retrieved and sonde-estimated refractivity, respectively. The mean and standard deviation of the fractional difference were calculated for each area (or sonde station) and will be used for discussions on the quality of COSMIC RO soundings in the following section.

\section{RESULTS}

Figure 1 shows the mean and standard deviation of frac-

Table 2. List of Radiosonde Stations in the Western Pacific.

\begin{tabular}{lccc}
\hline \multicolumn{1}{c}{ Station } & Latitude & Longitude & Elevation [m] \\
\hline Yap Island & $9.48^{\circ} \mathrm{N}$ & $138.08^{\circ} \mathrm{E}$ & 17 \\
Koror, Palau Island & $7.33^{\circ} \mathrm{N}$ & $134.48^{\circ} \mathrm{E}$ & 33 \\
Ponape Island & $6.97^{\circ} \mathrm{N}$ & $158.22^{\circ} \mathrm{E}$ & 46 \\
Truk/Moen Island & $7.47^{\circ} \mathrm{N}$ & $151.85^{\circ} \mathrm{E}$ & 2 \\
Majuro, Marshall Islands & $7.08^{\circ} \mathrm{N}$ & $171.38^{\circ} \mathrm{E}$ & 3 \\
Guam, Mariana Islands & $13.55^{\circ} \mathrm{N}$ & $144.83^{\circ} \mathrm{E}$ & 111 \\
\hline
\end{tabular}


Table 3. List of ozonesonde stations in polar areas.

\begin{tabular}{lccc}
\hline \multicolumn{1}{c}{ Station } & Latitude & Longitude & Elevation [m] \\
\hline Neumayer & $70.65^{\circ} \mathrm{S}$ & $8.26^{\circ} \mathrm{W}$ & 38 \\
Syowa & $69.00^{\circ} \mathrm{S}$ & $39.58^{\circ} \mathrm{E}$ & 21 \\
Ny-Ålesund & $78.93^{\circ} \mathrm{N}$ & $11.95^{\circ} \mathrm{E}$ & 11 \\
Eureka & $79.99^{\circ} \mathrm{N}$ & $85.94^{\circ} \mathrm{W}$ & 10 \\
Churchill & $58.74^{\circ} \mathrm{N}$ & $94.07^{\circ} \mathrm{W}$ & 30 \\
\hline
\end{tabular}

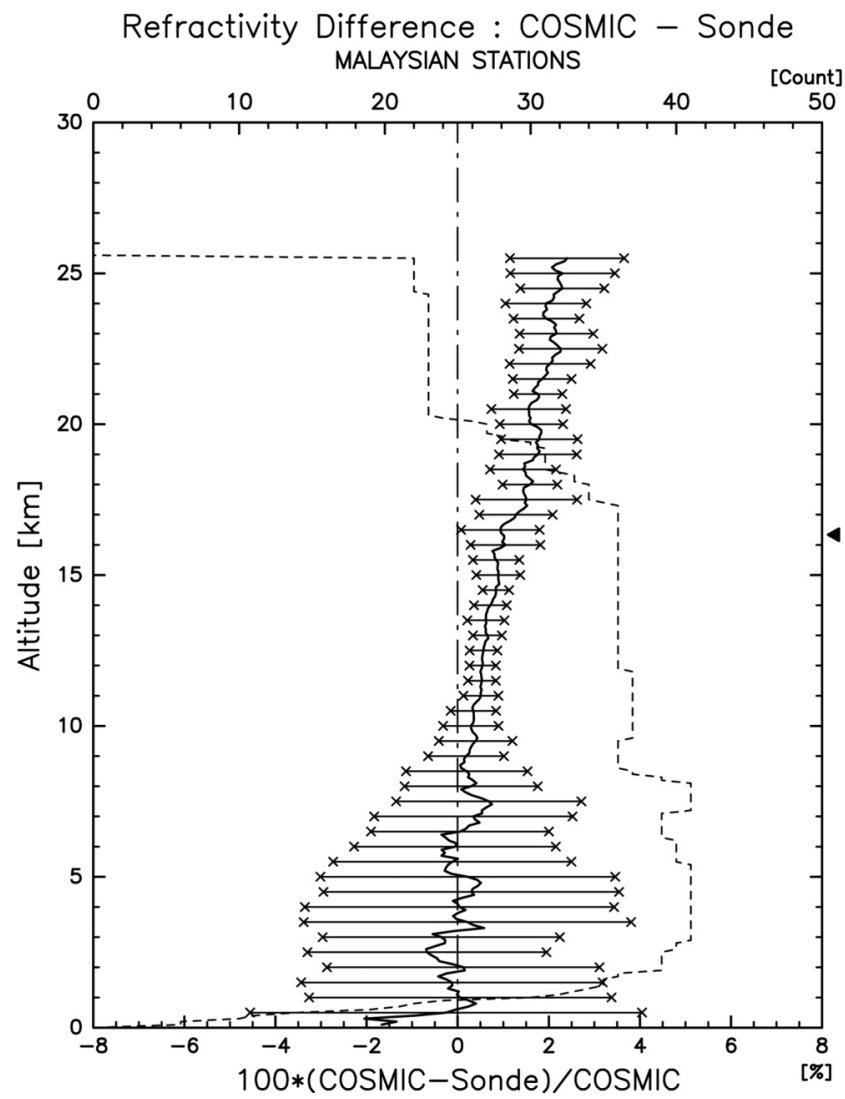

Fig. 1. The mean and standard deviation of fractional differences in refractivity between COSMIC RO and radiosonde soundings for Malaysian stations listed in Table 1. The thick solid line is the mean bias while the cross with traverse line shows the standard deviation at every $0.5 \mathrm{~km}$ altitude. The dashed line is the number of matches used for the statistical comparisons at each altitude. The triangle (4) on the right $y$-axis indicates the average tropopause altitude at $16.3 \mathrm{~km}$ (with standard deviation of $0.5 \mathrm{~km}$ ).

tional differences between COSMIC RO and radiosonde refractivity profiles for the six observation sites in Malaysia. The mean absolute difference profile demonstrates a good agreement between COSMIC RO and radiosonde soundings through the troposphere (except the vicinity of the surface) with less than a $1 \%$ bias. The bias fluctuates around zero in the lower troposphere and is positive and reaches up to $1 \%$ near the average tropopause at $16.3 \mathrm{~km}$ (with a standard deviation of $0.5 \mathrm{~km}$ ), which was calculated using the WMO definition based on temperature lapse rate (WMO 1957). As is clearly shown in the lower stratosphere, the fractional difference of refractivity increases at higher altitudes and achieves about a $2 \%$ bias (corresponding to about $0.2 \mathrm{~N}$ ) at $25 \mathrm{~km}$, around the highest altitude of the comparisons due to the availability of radiosonde soundings over Malaysia. Although only a small bias is observed in the lower troposphere, we see a large standard deviation below $9 \mathrm{~km}$, which becomes larger in approaching the surface (about $3.5 \%$ at $3 \mathrm{~km}$ ). This means that refractivity profiles retrieved from the COSMIC RO soundings have sometimes positive, otherwise negative, differences from collocated sonde data in the lower troposphere probably because of highly variable distribution of water vapor in the Southeast Asian monsoon region. A very small standard deviation (less than $0.5 \%$ ) in the upper troposphere $(10-15 \mathrm{~km})$ is evident along with low positive bias $(0.3$ $0.8 \%$ ). The altitude range corresponds to a few kilometers just below the tropopause level $(16.3 \pm 0.5 \mathrm{~km})$ where the effect of humidity is almost negligible and small-scale wave structures, if any, might not have an amplitude large enough to cause significant retrieval error for $\mathrm{RO}$ refractivity.

The same statistical comparison was performed for the tropical Western Pacific islands and the result is shown in Fig. 2. We see very similar characteristics to those found for the Malaysian stations as mentioned above, that is, a low bias (less than 1.5\%) throughout the troposphere with a positive bias becoming larger with increasing altitude in the lower stratosphere, a very small standard deviation (less than $0.5 \%$ ) for a few kilometers below the tropopause level (at $16.3 \mathrm{~km}$ in average with standard deviation of $0.6 \mathrm{~km}$ ), and large variability in the lower troposphere. The similarities should be reasonable since the two regions are located geographically adjacent to each other. A negative bias below $2 \mathrm{~km}$, which reaches up to about $2 \%$ in the lowest level, is seen in both Figs. 1 and 2. This can be attributed to the negative retrieval error in refractivity in the tropical lower troposphere (e.g., Rocken et al. 1997; Ao et al. 2003; Sokolovskiy 2003). A sharp vertical gradient of refractivity, or superrefraction, might often occur, which leads to the negative bias in the atmospheric boundary layer in tropics. It appears that, on the other hand, the standard deviation in the lower troposphere (excluding near-surface levels) is larger in Western Pacific (reaching up to 5\% around $3 \mathrm{~km}$ ) than in Malaysia (3.5\% at most). This may be suggesting different weather conditions (e.g., convective activity) between the neighboring areas, as expected in the previous section, which could cause more inhomogeneous water vapor distribution around the Western Pacific islands during the period investigated. Note that the statistical comparisons for both the two tropical regions were done using data only for the latter half of 2006. Further comparisons with more collo- 


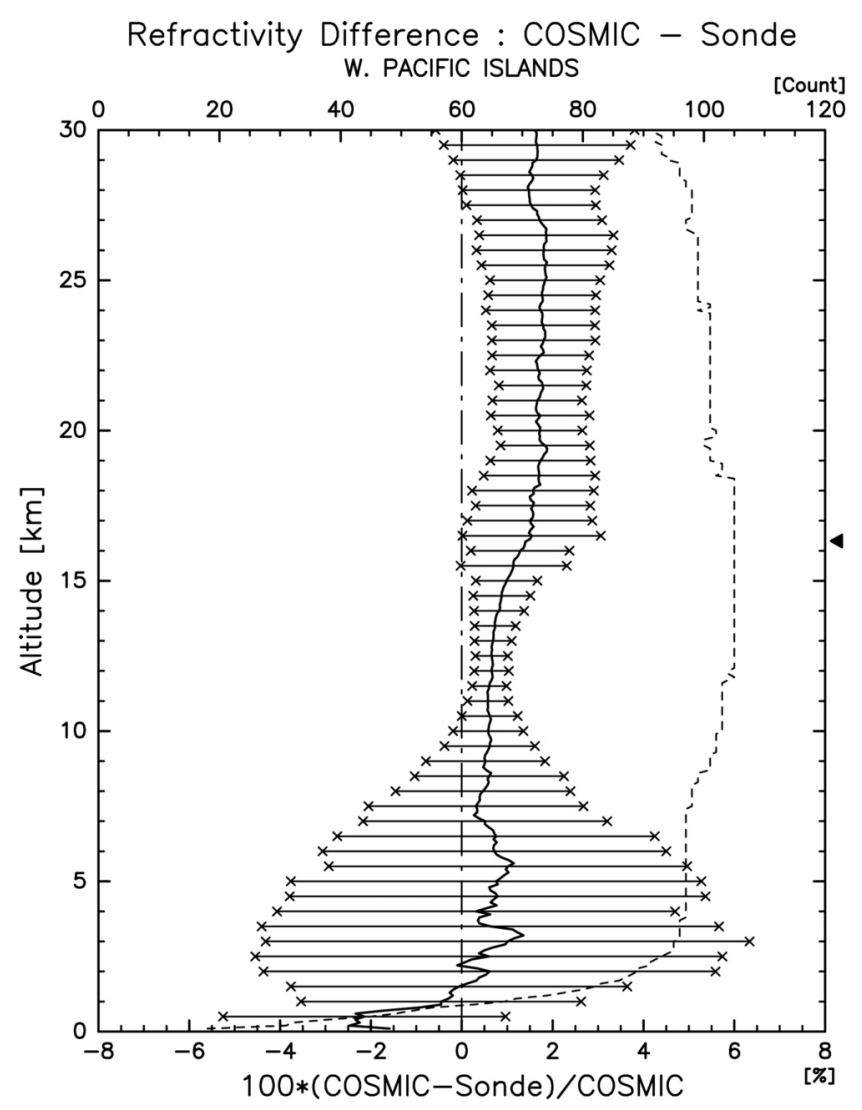

Fig. 2. The mean and standard deviation of fractional differences in refractivity between COSMIC RO and radiosonde soundings for Western Pacific islands listed in Table 2. The lines and marks are same as in Fig. 1. The average tropopause altitude is $16.3 \mathrm{~km}$ (with standard deviation of $0.6 \mathrm{~km}$ ).

cated data are necessary to investigate regional and seasonal characteristics of the quality of COSMIC RO soundings.

We here discuss results of statistical comparisons of COSMIC RO refractivities with ozonesonde measurements in the polar areas, where smaller deviations from the sonde observations in the lower troposphere are expected due to much less humidity compared to the tropical regions mentioned above. Figure 3 shows mean fractional differences for the Antarctic and Arctic regions. Since humidity data were not available for the ozonesonde soundings at Syowa, refractivities were calculated without partial pressure of water vapor, that is, by neglecting the second term in Eq. (1). Results of the statistical comparisons at Neumayer and Syowa, therefore, are shown respectively instead of merging them to represent the Antarctic area. On the other hand, all fractional differences at the three Arctic stations were averaged because there were only 11 matches available for the three stations during 2006. The left panel in Fig. 3 for Neumayer reveals extremely good agreement between COSMIC RO and sonde refractivities from the surface to about $19 \mathrm{~km}$ (throughout troposphere including lowermost stratosphere) with a $0.5 \%$ bias and $1 \%$ standard deviation at most (except for slightly larger bias around $9 \mathrm{~km}$ ). Above that altitude the bias becomes positive and larger with higher altitudes (though it somewhat decreases around $25 \mathrm{~km}$ ), which reaches to about $1 \%$ (corresponding to $0.1 \mathrm{~N}$ ) at $23-24 \mathrm{~km}$. A relatively smaller standard deviation is seen around $3-7 \mathrm{~km}$ below the tropopause level (at $10.6 \mathrm{~km}$ in average with standard deviation of $1.6 \mathrm{~km}$ ). As we have expected, standard deviation in the lower troposphere is much smaller ( $1 \%$ at most even below $5 \mathrm{~km}$ ) than in the tropical regions (as much as $3.5-5 \%$ around $3 \mathrm{~km}$ ). At Syowa the statistical comparison (middle panel in Fig. 3) shows the similar characteristics. The profile of mean fractional difference between COSMIC and ozonsonde refractivities fluctuates within $\pm 1 \%$ from 5 to about $21 \mathrm{~km}$ with standard deviation of less than $1 \%$. In the lowest $5 \mathrm{~km}$ positive bias is evident due to discounting humidity when calculating the sonde refractivity as mentioned above. The contribution of humidity to refractivity in the lowermost troposphere was examined using the ozonesonde measurements at Neumayer and about $0.5 \%$ (around $5 \mathrm{~km}$ ) to $2.5 \%$ (near the surface) of refractivity was accounted for by the effect of humidity. This implies that the large positive bias below $5 \mathrm{~km}$ at Syowa would almost disappear if humidity measurements were available. In the stratosphere the bias becomes positive and larger above $17 \mathrm{~km}$ as was the case with the comparison at Neumayer. We see relatively a smaller standard deviation between 6 and $8.5 \mathrm{~km}$, below the tropopause level (at $11.4 \mathrm{~km}$ in average with standard deviation of $2.1 \mathrm{~km}$ ). The result of a statistical comparison for the three Arctic stations (right panel in Fig. 3) also looks similar to that for Neumayer. The relatively smaller variation below the tropopause level (at $9.0 \mathrm{~km}$ in average with standard deviation of $0.9 \mathrm{~km}$ ) is recognized around $4-8 \mathrm{~km}$. The stratospheric positive bias (above 18 $20 \mathrm{~km}$ ) becomes larger with altitude (about $1 \%$ at $25 \mathrm{~km}$ ), though the standard deviation is suppressed by about a factor of 2 compared to that for the Antarctic stations. Agreement between COSMIC RO and sonde refractivities looks good (1\% bias at most with $1-1.5 \%$ standard deviation) except for slightly larger difference and variation near the surface and around $10 \mathrm{~km}$. As is well-known, the sharpness of polar tropopause defined by temperature gradient becomes highest in summer while lowest in winter (Zängl and Hoinka 2001). The highest sharpness of tropopause is seen in the Arctic region during NH summer (Schmidt et al. 2005). The detailed investigation by Zängl and Hoinka (2001) revealed that its annual cycle and regional differences are primarily determined by the mean static stability of the lower troposphere. Such a sharp tropopause associated with sudden refractivity change may cause some retrieval error in a COSMIC profile. For the Arctic stations the COSMIC-collocated sonde profiles in July to August 2006 really have sharp temperature tropopauses around $10 \mathrm{~km}$ (at $10.1 \mathrm{~km}$ in average, as indicated by asterisk on the right y-axis of Fig. 3) and large fractional differences between COSMIC and sonde 


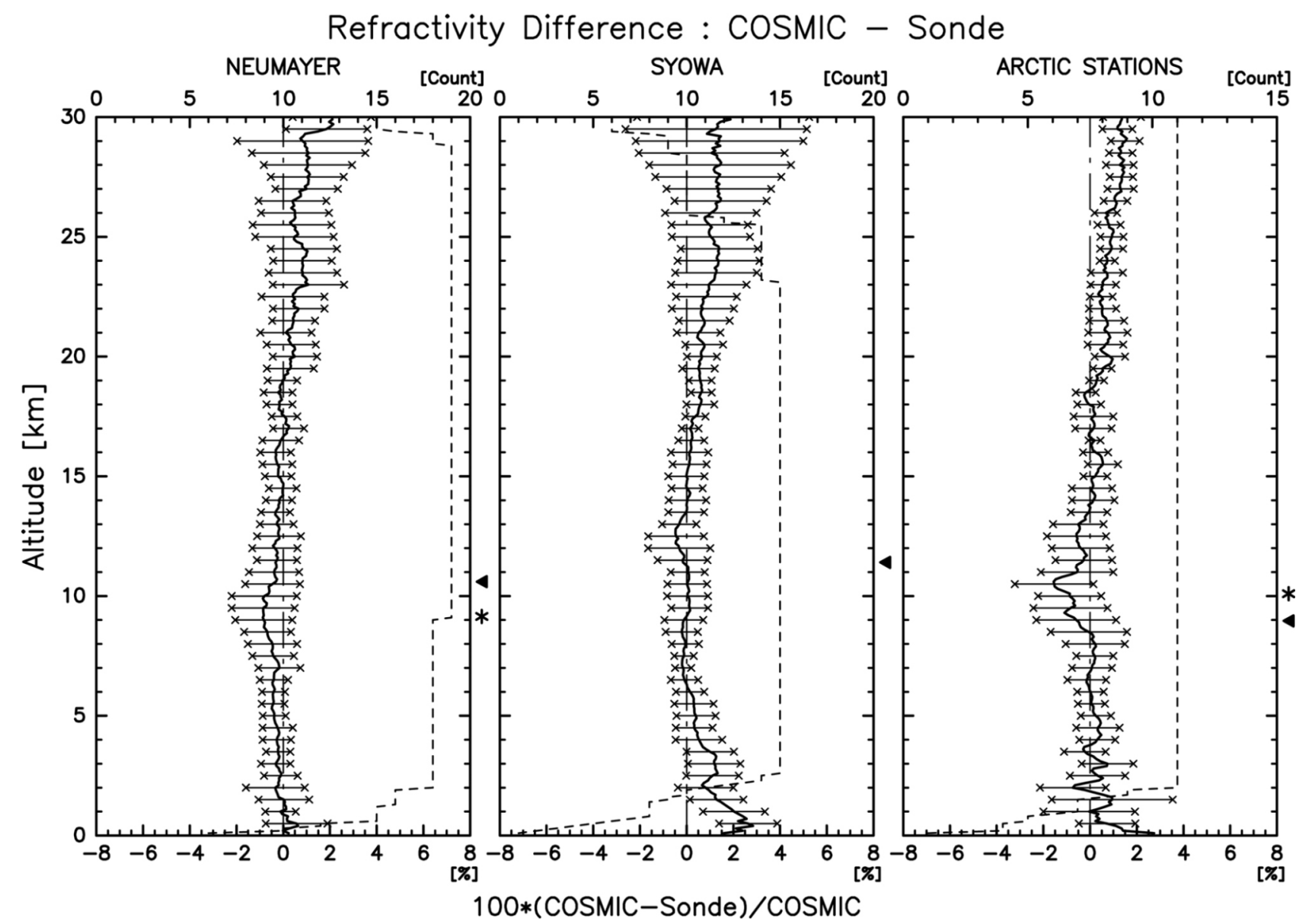

Fig. 3. The mean and standard deviation of fractional differences in refractivity between COSMIC RO and radiosonde soundings for polar areas listed in Table 3. Ozonesonde data are used instead of radiosonde. For Neumayer (left), for Syowa (middle), and for the Arctic stations (right). The lines and marks are same as in Fig. 1. The average tropopause altitudes are $10.6 \mathrm{~km}$ (Neumayer), $11.4 \mathrm{~km}$ (Syowa), and $9.0 \mathrm{~km}$ (Arctic stations), respectively, The asterisks $(*)$ on the right y-axis for Neumayer (at $9.2 \mathrm{~km}$ ) and for the Arctic stations (at $10.1 \mathrm{~km}$ ) indicate the mean tropopause altitudes with sharp temperature change in the summer (December 2006 to February 2007 for Neumayer while July to August 2006 for the Arctic stations). Note that there were no collocated sonde profiles with sharp summer tropopause at Showa.

refractivities are observed there as well (not shown). The relatively larger bias and standard deviation near $10 \mathrm{~km}$ in the statistical comparison, therefore, could be attributed to the summer polar tropopause with sharp temperature change. A similar statement applies to the slightly larger bias and standard deviation seen around $9 \mathrm{~km}$ in the statistical comparison at Neumayer (left panel in Fig. 3). Note that there are no collocated sonde profiles with sharp temperature tropopause in the summer (December to February) at Syowa. It should be mentioned that a synoptic-scale upper tropospheric anticyclone (typically accompanied with a thin, stable layer above) is also able to enhance the sharpness of tropopause (Wirth 2000; Zängl and Hoinka 2001).

\section{SUMMARY}

In this study COSMIC RO soundings were compared with high-resolution balloon-borne (radiosonde and ozone- sonde) observations in terms of refractivity in tropical and polar regions. From the statistical comparisons (i.e., mean and standard deviation of fractional differences between COSMIC RO and sonde refractivities) for Malaysia, Western Pacific islands, and the polar areas, we found some common features: 1) good agreement between COSMIC $\mathrm{RO}$ and sonde profiles throughout the troposphere (1-1.5\% difference at most); 2) a positive bias which grows with altitude (1-2\% difference around $25 \mathrm{~km})$ in the stratosphere; and 3 ) very small standard deviations (about $0.5 \%$ or less) for a few kilometers below the tropopause level. The standard deviation in the lower troposphere was much smaller in the polar areas with dry air $(1-2 \%$ at most $)$ than in the tropics with moisture-rich air (reaching up to $3.5-5 \%$ ). This paper has reported preliminary results of validation of COSMIC RO refractivity profiles. The comparisons with high-resolution sonde observations were restricted in time (for the latter half of 2006, along with some 2007 data used 
for the Antarctic area) and geographical locations. Finally, with the advent of more and more COSMIC RO data and independent observations, more and various investigations on the quality of COSMIC RO soundings will be conducted.

Acknowledgements We would like to thank Taiwan's National Space Organization (NSPO) and the University Corporation for Atmospheric Research (UCAR) for the COSMIC RO data, Malaysian Meteorological Department for the radiosonde data over Malaysia, NOAA/NCDC and SPARC data center for the radiosonde data from the tropical Western Pacific islands, and WOUDC for the ozonesonde data. This work was done as a part of Japan Earth Observation System (EOS) Promotion Program funded by the Ministry of Education, Culture, Sports, Science and Technology of Japan. The GFD-DENNOU Library was used for the figures.

\section{REFERENCES}

Ao, C. O., T. K. Meehan, G. A. Hajj, A. J. Mannucci, and G. Beyerle, 2003: Lower troposphere refractivity bias in GPS occultation retrievals. J. Geophys. Res., 108, 4577, doi: 10.1029/2002JD003216. [Link]

Fjeldbo, G., A. J. Kliore, and V. R. Eshelman, 1971: The neutral atmosphere of Venus as studied with the Mariner $\mathrm{V}$ radio occultation experiments. Astron. J., 76, 123-140, doi: 10.1086/111096. [Link]

Fujiwara, M., M. Shiotani, F. Hasebe, H. Vömel, S. J. Oltmans, P. W. Ruppert, T. Horinouchi, and T. Tsuda, 2003: Performance of the Meteolabor "Snow White" chilled-mirror hygrometer in the tropical troposphere: Comparisons with the Vaisala RS80 A/H-Humicap sensors. J. Atmos. Ocean. Technol., 20, 1534-1542, doi: 10.1175/1520-0426 (2003)020<1534:POTMSW>2.0.CO;2. [Link]

Gorbunov, M. E., 2002: Canonical transform method for processing radio occultation data in lower troposphere. Radio Sci., 37, 1076, doi: 10.1029/2000RS002592. [Link]

Gorbunov, M. E., A. S. Gurvich, and Luis Kornblueh, 2000: Comparative analysis of radioholographic method of processing radio occultation data. Radio Sci., 35, 1025-1034, doi:10.1029/1999RS002247. [Link]

Hajj, G. A., C. O. Ao, B. A. Iijima, D. Kuang, E. R. Kursinski, A. J. Mannucci, T. K. Meehan, L. J. Romans, M. de la Torre Juarez, and T. P. Yunck, 2004: CHAMP and SAC-C atmospheric occultation results and intercomparisons. J. Geophys. Res., 109, D06109, doi: 10.1029/2003JD003909. [Link]

Jensen, A. S., M. S. Lohmann, H. H. Benzon, and A. S. Nielsen, 2003: Full spectrum inversion of radio occultation signals. Radio Sci., 38, 1040, doi: 10.1029/2002RS002763. [Link]

Kuo, Y. H., T. K. Wee, S. Sokolovskiy, C. Rocken, W. Schreiner, D. Hunt, and R. A. Anthes, 2004: Inversion and error estimation of GPS radio occultation data. J. Meteorol. Soc. Jpn., 82, 507-531, doi: 10.2151/jmsj.2004.507. [Link]

Kuo, Y. H., W. S. Schreiner, J. Wang, D. L. Rossiter, and Y.
Zhang, 2005: Comparison of GPS radio occultation soundings with radiosondes. Geophys. Res. Lett., 32, L05817, doi: 10.1029/2004GL021443. [Link]

Kursinski, E. R., G. A. Hajj, J. T. Schofield, R. P. Linfield, and K. R. Hardy, 1997: Observing Earth's atmosphere with radio occultation measurements using the Global Positioning System. J. Geophys. Res., 102, 23,429-23,465, doi: 10.1029/97JD01569. [Link]

Luers, J. K. and R. E. Eskridge, 1998: Use of radiosonde temperature data in climate studies. J. Climate, 11, 1002-1019, doi: $10.1175 / 1520-0442(1998) 011<1002$ :UORTDI $>2.0$. $\mathrm{CO} ; 2$. [Link]

NCDC (National Climatic Data Center), 1998: Data documentation for data set rawinsonde 6-second data TD6211, Natl. Clim. Data Cent., Asheville, N. C.

Rocken, C., R. Anthes, M. Exner, D. Hunt, S. Sokolovskiy, R. Ware, M. Gorbunov, W. Schreiner, D. Feng, B. Herman, Y. H. Kuo, and X. Zou, 1997: Analysis and validation of GPS/MET data in the neutral atmosphere. J. Geophys. Res., 102, 29849-29866, doi:10.1029/97JD02400. [Link]

Rocken, C., Y. H. Kuo, W. Schreiner, D. Hunt, and S. Sokolovskiy, 2000: COSMIC system description. Terr. Atmos. Ocean. Sci., 11, 21-52.

Schmidt, T., S. Heise, J. Wickert, G. Beyerle, and C. Reigber, 2005: GPS radio occultation with CHAMP and SAC-C: Global monitoring of thermal tropopause parameters. Atmos. Chem. Phys., 5, 1473-1488.

Sokolovskiy, S., 2003: Effect of superrefraction on inversions of radio occultation signals in the lower troposphere. Radio Sci., 38, 1058, doi: 10.1029/2002RS002728. [Link]

Sokolovskiy, S., Y. H. Kuo, C. Rocken, W. S. Schreiner, D. Hunt, and R. A. Anthes, 2006: Monitoring the atmospheric boundary layer by GPS radio occultation signals recorded in the open-loop mode. Geophys. Res. Lett., 33, L12813, doi: 10.1029/2006GL025955. [Link]

Sokolovskiy, S. V., 2001a: Modeling and radio occultation signals in the moist troposphere. Radio Sci., 36, 441-458, doi: 10.1029/1999RS002273. [Link]

Sokolovskiy, S. V., 2001b: Tracking tropospheric radio occultation signals from low Earth orbit. Radio Sci., 36, 483-498, doi: 10.1029/1999RS002305. [Link]

Wang, J., D. J. Carlson, D. B. Parsons, T. F. Hock, D. Lauritsen, H. L. Cole, K. Beiere, and E. Chamberlain, 2003: Performance of operational radiosonde humidity sensors in direct comparison with a chilled mirror dew-point hygrometer and its climate implication. Geophys. Res. Lett., 30, 1860, doi: 10.1029/2003GL016985. [Link]

Wang, L., M. A. Geller, and M. J. Alexander, 2005: Spatial and temporal variations of gravity wave parameters. Part I: Intrinsic frequency, wavelength, and vertical propagation direction. J. Atmos. Sci., 62, 125-142, doi:10.1175/JAS3364.1. [Link]

Ware, R., C. Rocken, F. Solheim, M. Exner, W. Schreiner, R. Anthes, D. Feng, B. Herman, M. Gorbunov, S. Sokolovskiy, K. Hardy, Y. Kuo, X. Zou, K. Trenberth, T. Meehan, 
W. Melbourne, and S. Businger, 1996: GPS sounding of the atmosphere from low Earth orbit: Preliminary results. Bull. Amer. Meteor. Soc., 77, 19-40, doi: 10.1175/15200477(1996)077<0019:GSOTAF>2.0.CO;2. [Link]

Wirth, V., 2000: Thermal versus dynamical tropopause in uppertropospheric balanced flow anomalies. Quart. J. Roy. Meteor.
Soc., 126, 299-317, doi: 10.1002/qj.49712656215. [Link]

WMO, 1957: Meteorology-A three dimensional science. WMO Bull., 6, 134-138.

Zängl, G. and K. Hoinka, 2001: The tropopause in the polar regions. J. Climate, 14, 3117-3139, doi: 10.1175/1520-0442 (2001)014<3117:TTITPR>2.0.CO;2. [Link] 